\title{
Water and the Plant
}

$\mathrm{P}^{\mathrm{R}}$ ROF. E. J. SALISBURY delivered the Masters Lectures of the Royal Horticultural Society in March of last year. He spoke on "The Plant and its Water Supply", and the text is now published in the Society's Journal (62, Pts. 10 and 11, Oct. and Nov. 1937). It provides a synopsis of present-day knowledge which should be in the hands of every teacher and research worker in botany.

Prof. Salisbury ministered to the modern necessity for defining what is meant by water, for he considered some of the botanical implications of heavy water. A plant does not have a uniform water requirement throughout its period of growth, and the work of B. N. and B. R. Singh was quoted to show that seedlings and plants about to flower have greater demands than at other stages. Soil conditions naturally play a large part in the supply of water, and the physical forces which are active therein were reviewed in a succinct manner. Recent work upon the extent of root systems, the suction pressures required to transfer water from the soil to the plant, the appearance of osmotic gradients within the root and shoot, the numbers and behaviour of stomata, and the occurrence of hydathodes and nectaries, was marshalled to provide a basis for estimation of a plant's balance of water.

Several external factors may affect these processes. The root system may be diminished by competition or lack of phosphate in the soil, and shoot development is dependent upon proper extension of the root. The intake of sufficient mineral matter and of the rarer essential elements is also conditional upon an adequate area of absorption. It is interesting to note that gold is now enumerated among the elements present in small quantities in the tissues of some plants. It is found in the ash of Equisetum arvense, but not in amount sufficient "either to justify its cultivation, or even compensate us for its presence". Plants may also take in some water through the leaves, and the recovery of wilted shoots during the night is probably due very largely to this agency.

The mechanics of water transfer along the stem was also passed under review by Prof. Salisbury. Rates and pressures of the transpiration stream were enumerated. Investigations by Keinholz and by McDougall seem to show that a woody tree is not a rigid system, for the trunk contracts slightly during the day, and recovers at night.

The numbers of stomata upon the leaf of a plant may vary with soil conditions, being crowded when the plant grows in a dry situation, and sparser under wet conditions. Some plants grow better in dry air, while others flourish more in a moist atmosphere. The rate of water loss also depends upon the difference in temperature between the leaf and the surrounding air, whilst wind, of course, increases transpiration.

One cannot escape the conclusion, on reading Prof. Salisbury's lecture, that botanical research owes a great deal to the simplest methods. Measurements of temperature, humidity, water contents and organic matter contents, leaf areas and root lengths, contribute to a very convincing philosophy of the water relations of a plant, and also provide much practical knowledge which can be used directly by the gardener.

\section{Telegraphy and Telephony Progress in the General Post Office}

\begin{abstract}
$\mathrm{A}^{\mathrm{T}}$
$T$ the Institution of Civil Engineers on January 11, Sir George Lee, engineer-in-chief to the Post Office, read an instructive paper on recent and future developments in telephony and telegraphy and on the conveyor and machine systems in postal work. The aim of the developments is reduction of costs or higher precision in transmission. The change in the increase in the number of telephones from 73,000 per annum in 1931 , to 250,000 per annum in 1937, and the 50 per cent increase in the traffic in telegraphy due to the new tariffs, shows that such steps are desirable.

It was pointed out that by carrier-cables the speed of transmission in telephony has been increased from about 20,000 miles per second to six times that amount. The use of these cables also reduces the difficulties met with owing to the fact that waves of different frequencies travel with different velocities. It is fortunate that the ear is very accommodating both for electric wave 'echoes' and 'phase delay'. It is interesting to find that the beams of light which constitute a television picture, in order to be portrayed accurately and quickly, require, at the present time, a band width of $1,600,000$ cycles, whilst com-
\end{abstract}

mercial telephony only requires 2,400. Circuits for music require 9,000. 'Thus the new 'coaxial' cable is expected to carry 400 telephone conversations simultaneously, although it only provides one television channel.

Sir George referred to radio telephone communications by the use of ultra-short waves. Examples were given of commercial communications within the optical range, in the radio telephone system across the North Channel between Scotland and Northern Ireland. This is done by using two stations well above sea-level. A distance of approximately 36 miles is traversed, the path being entirely optical. As an example of a service working over a nonoptical range, the radio telephone service between England and Guernsey was cited. It was attempted at first to cover a range of 105 miles, the optical range being only 45 miles. With this arrangement it was found that as late autumn changed into winter, the received energy was only about one thousandth of that received during the summer. A change in the stations selected reduced the distance to 85 miles; this worked satisfactorily, the working range being $1 \cdot 73$ times the optical distance. 